\title{
Testing New Lighting Technology in a Park Pedestrian Area
}

\author{
Ari Lehtio, Tauno Perkiö* \\ Satakunta University of Applied Sciences, Finland
}

Copyright $@ 2015$ Horizon Research Publishing All rights reserved.

\begin{abstract}
European Union directives on ecodesign requirements of discharge lamps have also their effect on street lighting. The commonly used mercury vapor lamps have to be replaced starting from 2015. Pori, a middle sized city situated on the west coast of Finland, has about 17000 mercury discharge lamps for street lighting. This was the starting point for Pori Energia, the utility that takes care of public lighting in the city of Pori, and for Satakunta University of Applied Sciences (SUAS) to initiate an investigation of alternative lamps. This paper considers the results of a practical experiment of four lamp types applicable for street lighting: high pressure sodium lamp, metal halide lamp, inductive lamp and led lamp. The lamps were installed above a park pedestrian area and the illumination was measured in various circumstances in the winter. In addition, electric measurements were carried out in the Electric Laboratory of SUAS. Also a small scale opinion poll among the pedestrian area users was included in the research. The results show that the luminous flux of all of the new lamp types was higher than that of the old mercury lamps. This was clearly proved even when the aging factor was taken into account. The led lamp seems to be the best choice relative to illumination/power consumption ratio. The park pedestrian area users were also satisfied with the chromatic tone of the white led light. However, the led lamp technology is not in mature phase and using it widely may cause extraordinary costs in the infrastructure of electric networks.
\end{abstract}

Keywords Street Lighting, Illumination, Mercury Lamps, LED Lamps, Energy Saving

\section{Introduction}

Energy saving and ecological demands are important issues in the European Union. One sector where there is essential energy saving potential is illumination. That is why the EU Commission has given several directives that prevent putting into market products that cannot reach the rated luminous efficacy per electric power $(1 \mathrm{~m} / \mathrm{W})[1,2]$. The new regulations will become valid step by step. One milestone is the year 2015 when among other changes mercury discharge lamps will not meet the new requirements of power efficacy. The mercury vapor lamp is a very common lamp in street lighting and in other public places such as railway stations etc.

The led lamps and other energy saving lamps are becoming more widespread, while mercury lamps are disappearing from street lighting areas. However, the power supply systems of the new lighting technology introduce nonlinearities into the electric network. Therefore understanding the harmonic production complexion of the lamps becomes necessary. Many studies about the harmonic content on the electric current, power and apparent power of the lighting systems have been published to analyze the problems caused by the new lighting technology [3-6].

Pori Energia Ltd, the City of Pori and Satakunta University of Applied Sciences (SUAS) started a project in order to experiment alternative lamps for street lighting. Four different lamp types were selected for comparison: high pressure sodium lamp, metal halide lamp, induction lamp and led lamp. The test area was a park street devoted to pedestrians and cyclists. Before the project started the street was illuminated by mercury lamps. The illumination was first measured while the old mercury lamps were still in place and then the lamps were removed and the new lamps were installed on the same poles. Now new measurements could be made.

The Electric Laboratory of SUAS determined various parameters of the lamps. The most important measurements were the active and reactive power measurements and measurement of harmonic distortion. The opinion poll was also carried out among the street users on two successive days. Pori Energia informed people of the opportunity to tell one's opinion. About 110 persons took part in the poll.

\section{Illumination Measurements}

The first illumination measurement was made in winter 
conditions. This measurement was carried out with the old mercury vapor lamps in order to get a reference to further measurements of the other types of lamps. The temperature was $-4^{\circ} \mathrm{C}$ and there was snow on the ground. The measurement was made in the middle of the road at $1 \mathrm{~m}$ height. The illumination varied from lamp to lamp quite a lot but the maximum level was about 12 lux.

Next the old mercury vapor lamps were removed and other lamp types were installed. The same lamp poles were used; all lamps were installed at the height of 5 meters. Two lamps of each type were installed. Measurements were carried out in three phases: The first in February, the second in September and the last one in December. In this way it was possible to find out, how much the aging of the lamps decreased the illumination. The second aim was to see, whether the snowy circumstances have an effect on the illumination.

After about 2600 hours of use the illumination decreased as follows:

- High pressure sodium lamp: $16-18 \%$

- Metal halide lamp: $34-39 \%$

- Induction lamp: $12 \%$

- Led lamp: 7 - 10\%.

These results are only indicative, because only two lamps per lamp type were measured. In any case, it seems clear that the metal halide lamp was not able to compete with other types in this respect. The snowy environment increases somewhat diffused light, but the tests did not give any remarkable differences between the lamp types whether they were used in snowy or bare ground period. Fig. 1 depicts the illumination on the street level with the old mercury lamps and the new lamps. The lamps were installed to the same poles without any changes to the distance between the poles or to the height of the poles. That is why the illumination variation is quite large. The illumination variance could be diminished with proper optimization of the installation for each lamp type.

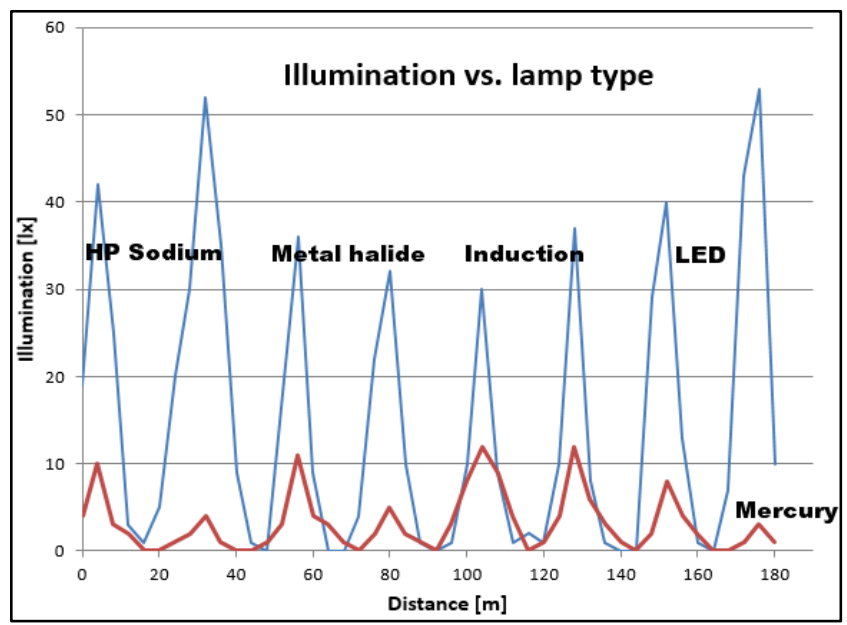

Figure 1. The illumination of the new lamp types and old mercury discharge lamp measured on the street level and in similar weather conditions
It is easy to see that the new lamp types give more light than the old mercury lamps. This is true even if the decrease of light production due to aging is taken into account. The white light led lamp seems to be the most efficient but the difference to the high pressure sodium lamp is relatively small. The very low illumination level between the lighting poles results from the poor construction of the lighting line of the park pedestrian area. The pole spacing has initially been designed to be too large which results into dark areas between the poles irrespective of the lamp type.

\section{Electric Measurements}

In the steady state the new lamps use considerably less real power than the old mercury lamps. In Table 1 we see the combined results of electric measurements.

Table 1. Electric measurement results of the lamps

\begin{tabular}{|c|c|c|c|c|c|c|}
\hline Lamp type & $\begin{array}{c}\mathrm{I}_{\mathrm{rms}} \\
{[\mathrm{A}]}\end{array}$ & $\begin{array}{c}\mathrm{P} \\
{[\mathrm{W}]}\end{array}$ & $\begin{array}{c}\mathrm{Q}_{50} \\
{[\mathrm{VAr}]}\end{array}$ & $\begin{array}{c}\mathrm{Q}_{\text {full }} \\
{[\mathrm{VAr}]}\end{array}$ & $\begin{array}{c}\mathrm{THD}_{\mathrm{F}} \\
{[\%]}\end{array}$ & $\mathrm{PF}(\mathrm{full})$ \\
\hline LED lamp & 0.355 & 42 & 13 & 70 & 155 & 0.51 \\
\hline $\begin{array}{c}\text { Induction } \\
\text { lamp }\end{array}$ & 0.239 & 54 & 9 & 32 & 7.0 & 0.86 \\
\hline $\begin{array}{c}\text { HP } \\
\text { Sodium } \\
\text { lamp }\end{array}$ & 0.427 & 94 & 1 & 31 & 30.9 & 0.95 \\
\hline $\begin{array}{c}\text { Metal } \\
\text { halide } \\
\text { lamp }\end{array}$ & 0.448 & 91 & 10 & 48 & 30.9 & 0.89 \\
\hline $\begin{array}{c}\text { Mercury } \\
\text { lamp (old) }\end{array}$ & 0.706 & 138 & 72 & 78 & 16.5 & 0.86 \\
\hline
\end{tabular}

The column $\mathrm{Q}_{50}$ means the reactive power measured at the frequency of $50 \mathrm{~Hz}$ and $\mathrm{Q}_{\text {full }}$ means the reactive power measured across all frequencies. The $\mathrm{THD}_{\mathrm{F}}$ is defined here as the harmonic content compared to the fundamental frequency of the waveform [7].

The harmonic content of the current increases considerably when the led lamps without filtering are used in street lighting. For example, the references $[8,9]$ present very similar THD values and current curves of the led lamps to those in Fig. 2. Our results concerning the HP sodium lamp are quite similar to the results presented in [3]. The THD value of the $150 \mathrm{~W}$ HP Sodium lamp in [3] is $34 \%$ and in our results the THD value is $30.9 \%$.

The RMS currents and the active powers seem to be what one could expect. The led lamp operates with the smallest active power, but the reactive power $\mathrm{Q}_{\text {full }}$ is very high. In fact, the spectral energy of the harmonics exceeds that of the fundamental wave $(50 \mathrm{~Hz})$. This is clearly seen in the value of total harmonic distortion $\mathrm{THD}_{\mathrm{F}}$.

According to the measurements the peak value of the led lamp is $1.2 \mathrm{~A}$ (see Fig 2) while the RMS value is $0.355 \mathrm{~A}$. Supposing that there are no other loads connected to the power transformer we can estimate that the maximum capacity of the distribution transformer is lowered by a factor

$$
k=\frac{\sqrt{2} I_{r m s}}{I_{\text {peak }}}=0.42
$$




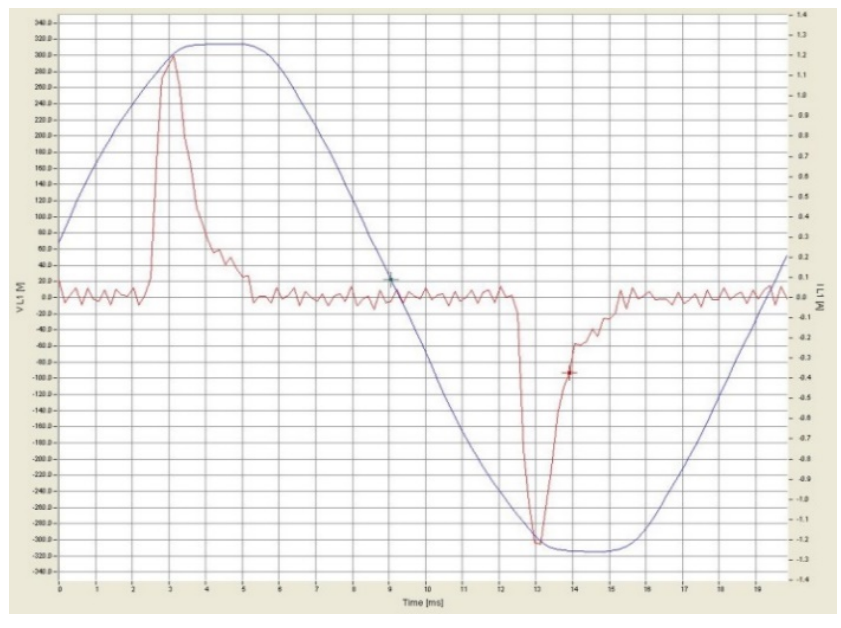

Figure 2. The voltage and current of the LED lamp

This means extra costs in the electric distribution network if led lamps with such power supplies are widely used. In this case the supply transformer cannot be dimensioned according to the total active power because the extra eddy-currents cause excessive heating of the transformer. The Electricity Utility may be forced to install a bigger and more expensive supply transformer. Another reason that may increase the building costs of the electricity distribution system is the harmonic load of phases, which results in extra current in the ground conductor (the sum of the third harmonic currents). In that case the third harmonic filter is needed in the ground point of the transformer.

Fig 3 depicts the active power consumption of the lamps after being switched on.

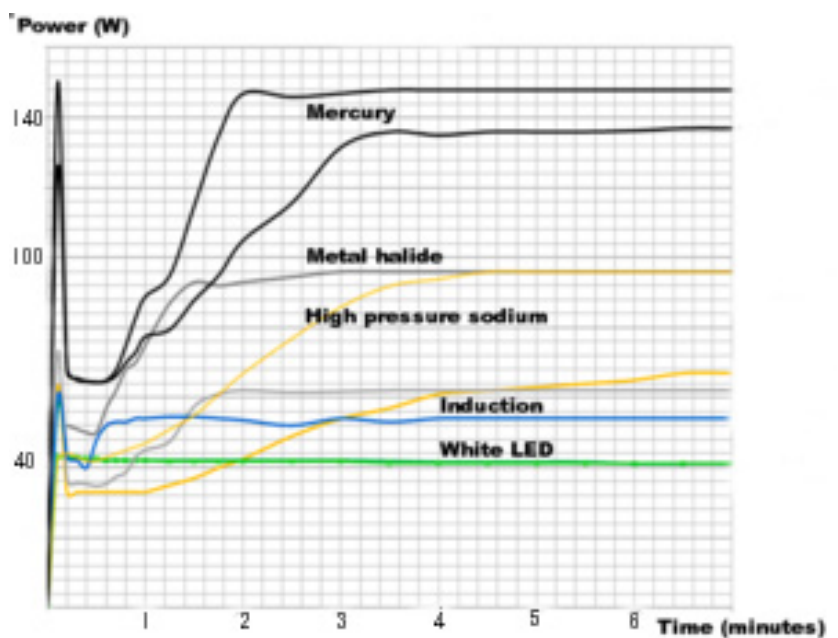

Figure 3. The power of the lamps after switched on

All the lamps reach the steady state within five minutes. As seen in the figure 3 the discharge lamps take a high power transient at the moment of turn-on. Then the power decreases remarkably and after one minute the power increases slowly into the final steady state value.

The induction lamp has only a small power transient at switch-on time and the led lamp behaves very nicely: led produces light immediately with final power.

\section{Opinion Poll}

The opinion poll was carried out on two evenings in the winter among the pedestrian area users. The sampling method was very straightforward: Everyone who walked on the street was asked a few questions concerning the lighting of the tested lamps. In this way altogether 110 persons gave their opinion. The pedestrians could only estimate the illumination level and the chromatic tone of the installed lamps. No other viewpoints (technical or economic) were considered in the opinion poll.

The popularity of the white led lamp was very high. E.g. in answer to the question "which lamp would you wish to illuminate the streets in the City of Pori" the distribution of answers was as follows:

- $\quad$ High pressure sodium lamp $12.3 \%$

- Metal halide lamp $8.8 \%$

- Induction lamp $14.9 \%$

- White led lamp 51.8\%.

The result is depicted in Fig 4.

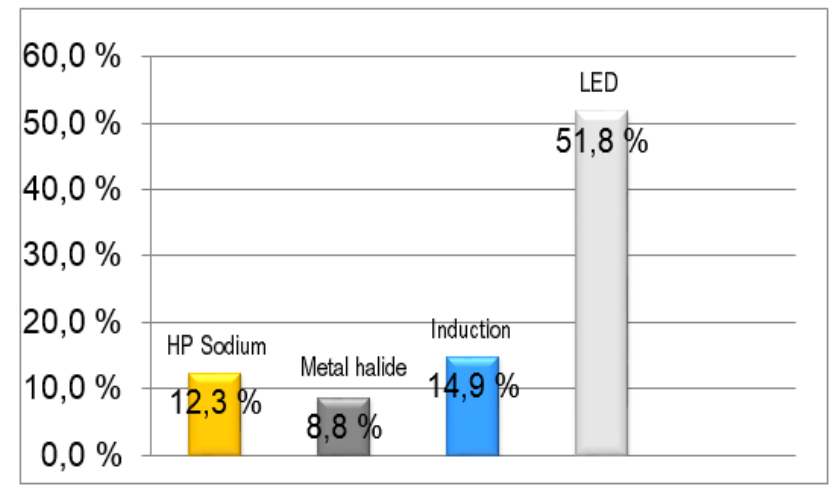

Figure 4. The results of the opinion poll

\section{Economic Consideration}

In the economic consideration there are many parameters. In this research the goal was to estimate the annual total costs of the metal halide, the high pressure sodium and the led lamp. The induction lamp was not included in this consideration because no comparable estimate of the lifetime of this lamp type was available. The lifetime costs of street lighting result from the price of lamps, the maintenance costs, the initial installing costs and the price of electricity. The calculation was based on the present value method.

The calculation presumes 35 years' usage and a $6 \%$ interest rate. The annual inflation rate was set to $2 \%$. The calculation was carried out using two values for the annual rise in the price of electricity ( $2 \%$ and $4 \%$ ). This is a quite moderate estimation because the price of electricity has risen annually on average $5.7 \%$ during the last few years in Finland.

According to the Electricity Utility (Pori Energia) the street lights are in operation about 3850 hours yearly. The 
calculation was done using the lifetimes of lamps that were stated by the manufactures, but the power consumptions were measured in the electric laboratory of SUAS. The used lifetimes and power consumptions were as follows:

- $\quad$ LED lamp $70000 \mathrm{~h}, 42 \mathrm{~W}$

- Metal halide lamp $13000 \mathrm{~h}, 91 \mathrm{~W}$

- High pressure sodium lamp 22000 h, 94 W.

The price of the led lamp was about 1.67 times the price of the metal halide lamp or the price of the high pressure sodium lamp. The installation costs are approximately the same. It is assumed that the metal halide lamp and the high pressure sodium lamp do not need any maintenance during their lifetime - they are simply replaced as their light production falls too low. On the other hand it was assumed that the led lamp needs only a minor maintenance (dust removal) three times during the lifetime.

The results of economic calculation are shown in Table 2 .

Table 2. Relative costs of the lamps in 35 year period

\begin{tabular}{|c|c|c|c|}
\hline $\begin{array}{c}\text { Raise of energy } \\
\text { price/year }\end{array}$ & LED lamp & $\begin{array}{c}\text { High P } \\
\text { sodium }\end{array}$ & $\begin{array}{c}\text { Metal halide } \\
\text { lamp }\end{array}$ \\
\hline $2 \%$ & 1110 & 1168 & 1384 \\
\hline $4 \%$ & 1210 & 1392 & 1601 \\
\hline
\end{tabular}

The led lamp seems to be the most economical solution although the initial investment is the highest. A rise in the energy price will emphasize the superiority of the led lamp. However, this simple consideration can be criticized. First of all, the lifetimes of lamps were adopted from lamp manufacturers' information. How is 'lifetime' defined? A common definition of lifetime is the number of hours of operation of lamps until $50 \%$ of them fail. Another definition is to measure the time when $50 \%$ of lamps have dropped their luminous flux to $70 \%$ or less from the initial value.

Both definitions should give approximately the same lifetime for the led lamp. It is impossible to measure its lifetime within the relatively short time period available for a project. If the lifetime of the led lamp is 70000 hours (a value given by the manufacturer), we should be ready to wait at least 8 years to get results from the measurements! A well-known fact is that the led lamp needs a proper cooling because high temperatures may shorten its lifetime remarkably. The led lamp does not radiate in the infrared zone like other lamp types but all the excessive heat energy must be conducted away with a heat sink. In Finland the outdoor temperature varies from -30 degrees Celsius to +30 degrees, which means high demands to the structure to the lamp. This is why the lifetime of a poorly designed led lamp may be shorter in practice than expected.

The metal halide lamp shows continuous decrease of luminous flux with time. This was clearly noticed also in this research (see section 2). The latter definition of lifetime is more adequate for metal halide lamps.

It seems that the manufactures of lamps use different definitions of the lamp lifetime depending on the lamp type. So the economic calculations will have extraneous uncertainty for this reason.

Another uncertainty is the change of lamp prices. The trend is that the led lamps become cheaper step by step. However, it is difficult to predict the future development of the relative prices of the lamp types.

\section{Conclusions}

In this research work mainly the technical viewpoints were considered but a small opinion poll was also carried out. The led lamp showed to be the lamp type of the future. The popularity of the led lamp was found to be wide according to the opinion poll carried out in our research work. Over the $50 \%$ of the respondents would like to illuminate the streets in the city of Pori with the white led lamp.

The led lamp seems to be also the most economical solution for the street lighting in the future. A rise in the energy price will stimulate the use of the led lamp.

However, the power supply unit of the led lamp must be well designed in order to avoid the difficulties described in section 3. Otherwise the quality of electricity will worsen and extra investments have to be done on electricity distribution infrastructure. If construction changes are necessary in the existing electricity distribution network due to the new lighting technology it certainly leads to the rise of the consumers' electric bill.

\section{REFERENCES}

\section{[1] EU directive 2005/32/EC}

[2] EU directive 2009/125/EC

[3] Manzano, E.R.; Carlorosi, M.; Tapia Garzon, M. Performance and Measurement of Power Quality Due to Harmonics from Street Lighting Networks. In Proceedings of the Conference on Renewable Energies and Power Quality (ICREPQ'09), Valencia, Spain, 15-17 April 2009.

[4] Pantaleone, G. Power electronics in public lighting systems: Are LEDs the only viable solution? Power Syst. Des. Eur. 2007, 4, 42-44.

[5] Uddin, S.; Shareef, H.; Mohamed, A.; Hannan, M.A. An Analysis of Harmonics from LED Lamps. In Proceedings of the Asia-Pacific Symposium on Electromagnetic Compatibility (APEMC), Singapore, 21-24 May 2012; pp. 837-840.

[6] Monte, K.R.; Sen, P.K. Compact Fluorescent Lamps and Their Effect on Power Quality and Application Guidelines. In Proceedings of the Industry Applications Society Annual Meeting (IAS), Houston, TX, USA, 3-7 October 2010.

[7] D. Shmilowitz: On the Definition of Total Harmonic Distortion and its Effect on Measurement Interpretation, IEEE Transactions on Power Delivery, Vol. 20, No. 1, January 2005 
[8] Dolara, A.; Faranda, R.; Guzzetti, S.; Leva, S. Power Quality in Public Lighting Systems. In Proceedings of the 14th International Conference on Harmonics and Quality of Power (ICHQP 2010), Bergamo, Italy, 26-29 September 2010.
[9] Dolara, A.; Falvo, M.C.; Faranda, R.; Grasselli, U.; Leva, S. Lighting systems: Power Consumptions and Harmonics Monitoring Survey. In Proceedings of the 3rd International Conference on Clean Electrical Power: Renewable Energy Resources Impact (ICCEP 011), Ischia, Italy, 14-16 June 2011; pp. 249-256. 